\title{
The Effect of Alpha-Blocker Treatment on Bladder Hypoxia Inducible Factor-1 Alpha Regulation during Lower Urinary Tract Obstruction
}

\author{
George Koritsiadis, Stavros I. Tyritzis, George Koutalellis, Andreas C. Lazaris, Konstantinos \\ Stravodimos
}

Department of Urology (GK, SIT, GK, KS) and Pathology (ACL), Athens University Medical School, LAIKO Hospital, Athens, Greece

\begin{abstract}
Aims: To determine whether $\alpha 1$-blocker treatment, in chronic bladder outlet obstruction (BOO), influences bladder tissue ischemia.

Materials and Methods: This prospective study included 60 patients with BOO, of which 40 were under $\alpha 1$-blocker medication and 20 without treatment. Patients underwent transurethral resection of the prostate (TURP) or suprapubic prostatectomy (SPP). Ten patients with non-muscle invasive bladder cancer underwent transurethral resection of the bladder tumor and served as the control group. Tissue specimens were immunohistochemically stained for hypoxia inducible factor- $1 \alpha(\mathrm{HIF}-1 \alpha)$.

Results: Bladder tissue from obstructed subjects showed high immunoreactivity to HIF-1 $\alpha$. The specimens from the control group, showed no or weak, mainly cytoplasmic immunoreactivity to HIF-1 $\alpha$. Patients under $\alpha$-blocker treatment did not differ in the number of HIF-1 $\alpha$ positive cells compared to subjects with no treatment (median number 86.8 [20-150] and 88.6 [0-175], respectively) ( $\mathrm{p}>0.05)$. The lowest bladder pressure at which HIF-1 $\alpha$ was up regulated, was detected at detrusor pressure Qmax (PdetQmax) $=60 \mathrm{~cm} \mathrm{H} 2 \mathrm{O}$.

Conclusions: Treatment with $\alpha$-blockers in obstructed patients considered as non-responders, does not result in HIF-1 $\alpha$ down regulation, thus bladder continues to be under chronic stress.
\end{abstract}

Key words: bladder; bladder outlet obstruction; hypoxia inducible factor-1; ischemia; alpha-blockers Int Braz J Urol. 2010; 36: 86-94

\section{INTRODUCTION}

First line treatment in patients with bladder outlet obstruction (BOO) is alpha1-adrenoreceptor antagonists (1). However, their contribution is limited mostly in alleviating benign prostatic hyperplasia $(\mathrm{BPH})$ symptoms rather than influencing disease progression, which is manifested as acute urinary retention or the need for invasive therapy (2).
There is evidence based on non-obstructed experimental models, that during the emptying phase, bladder pressure increases while oxygen wall tension decreases and returns to premicturition levels, shortly after voiding is completed. In the obstructed animal model however, the pressure generated is much higher and the bladder wall remains ischemic for several minutes even after micturition has ended (3). In BOO, blood flow to the bladder is inversely related to fill- 
ing, leading to severe hypoxia and consequent further damage to the detrusor (4).

Tissue hypoxia can be evaluated by measuring the levels of hypoxia inducible factor-1 $\alpha$ (HIF-1 $\alpha$ ). HIF- $1 \alpha$ is a multipotent protein activated in cells when they are under low oxygen tension, and functions as cellular regulator of oxygen. Its multipotency is demonstrated by its crucial role in angiogenesis through vascular endothelial growth factor (VEGF) up-regulation and the regulation of cellular metabolism in diseases such as stroke, heart attack and cancer, which generate a hypoxic microenvironment (5). The close association of hypoxia and HIF- $1 \alpha$ has been established in previous reports $(6,7)$, and this association provides the rationale of using this protein as a credible hypoxia marker. Yet, there is evidence of HIF$1 \alpha$ induction by non-hypoxic stimuli such as several growth factors, coagulation factors, vasoactive peptides, cytokines, metal ions or even mechanical stress (8). However, the pathway of their effect is based on reactive oxygen species production, which somehow counterintuitive is up-regulated by hypoxia $(9,10)$. Thus, independently of the type of stimulus, it seems that hypoxia is strongly related to HIF-1 $\alpha$ synthesis.

To our knowledge, there are no reported studies on the effect of $\alpha 1$-blockers in bladder metabolism and tissue hypoxia in patients with $\mathrm{BOO}$ and chronic obstructed bladders, respectively. We made the hypothesis that since $\alpha 1$-blockers used in BOO do not alleviate dramatically obstructive parameters, they would not impact on bladder tissue hypoxia. The aim of the present study was to examine tissue distribution of HIF- $1 \alpha$ in patients with BOO under $\alpha_{1}$-blocker medication, using urodynamic parameters and tissue immunohistochemical staining.

\section{MATERIALS AND METHODS}

\section{Patient Baseline Characteristics}

This prospective, non-blinded study took place from September 2004 to December 2006, including 60 patients with lower urinary tract symptoms (LUTS) suggestive of BOO secondary to BPH (study group), who all provided informed consent.
Ten patients with non-muscle invasive bladder cancer scheduled for transurethral resection (TUR-BT), without BOO or LUTS served as control group. Detrusor tissue was retrieved from normal appearing urothelium distant from the bladder cancer and the absence of cancer was verified microscopically.

Patients in the study group underwent detailed medical history, physical examination and urinalysis with laboratory blood tests. LUTS were classified according to International Prostate Symptom Score (IPSS). Maximum flow rate $\left(\mathrm{Q}_{\max }\right)$, post void residual volume (PVR), serum PSA and prostate volume (Vpr) were determined. Indications for surgery were IPSS $>20$, flow rate less than $15 \mathrm{~mL} / \mathrm{sec}$ and a history of acute urinary retention. In the 20 patients with $\mathrm{BOO}$ without receiving treatment, we performed urodynamic evaluation prior to surgery. The lowest detrusor pressure at max flow (PdetQmax), maximum detrusor pressure (Pdetmax) and detrusor closure pressure (PdetCL) were recorded.

The study group was further divided in those patients who were under tamsulosin $0.4 \mathrm{mg}$ ( 40 patients) and those who were not (20 patients). The two subgroups were well balanced regarding age, IPSS, Vpr and other comorbid conditions, (diabetes, hypertension, smoking, high cholesterol). Exclusion criteria in the study cohort comprised recurrent urinary tract infection, bladder lithiasis, low hematocrit level, and previous surgery to the bladder or the prostate. Exclusion criteria in the control group included IPSS $>7$, recurrent urinary tract infections, high volume disease, suspicion of in situ carcinoma, and previous TUR-BT.

\section{Tissue Procurement and Immunohistochemistry}

Bladder tissue was easily retrieved in patients who underwent suprapubic prostatectomy whilst, in patients who underwent a TURP, a cold cup biopsy was done in order to avoid thermal damage to the specimens. Tissue was always retrieved from the dome of the bladder. Tissue samples were fixed in buffered formalin. Paraffin-embedded sections were stained with standard hematoxylin and eosin. The primary antibody used for immunohistochemistry was antiHIF-1 $\alpha$ (Chemicon Inc., Tenecula, CA format: Purified immunoglobulin, clone: Chemicon MAB 5382 - anti- 
body specificity: HIF-1 $\alpha$, immunogen: fusion protein from amino acids $432-528$ of human HIF- $1 \alpha$, isotope: IgG2b) and was applied at a dilution of 1:200.

Antigen retrieval was performed by heating the slides with citrate-buffered solution in microwave oven for 5 minutes in two cycles. Envision (Dako, Denmark) was used as secondary antibody. Finally, diaminobenzidine was applied as chromogen and the slides were slightly counterstained with hematoxylin. In substitute negative controls, the primary antibody was omitted and replaced by phosphate-buffered saline.

Two pathologists unaware of the clinical data performed the assessment of staining. Where results were equivocal, the slides were jointly re-examined for a final consensus. A minimum of twenty randomly selected, high-power fields through the whole section was examined and not quantitative histology software was used.

The assessment of HIF- $1 \alpha$ was based on a previously described method (11). HIF-1 $\alpha$ immunoreactivity was expressed in nucleus and cytoplasm of stromal cells. The assessment of staining was carried out according to the number of positive cells and staining distribution. Specimens were grouped into high and low HIF-1 $\alpha$ reactivity using a cut off point of 80 reactive cells/slide, which represents the lowest 95\% CI value.

\section{Statistics}

Data were analyzed through descriptive statistics and for statistical reasons the categorical nature of HIF-1 $\alpha$ staining was used. Chi-square test was used to test statistical significance in categorical variables and odds ratios to quantify the strength of association. Differences of categories were evaluated with Kruskall-Wallis and analysis of variance when appropriate, Mann-Whitney-U and Student's-t-test were used to estimate differences among groups.

\section{RESULTS}

The examined baseline parameters of the patients are listed in Table-1. Differences between patients under $\alpha 1$-blocker medication $(\mathrm{n}=40)$ and without medication $(n=20)$ in terms of age, IPSS,
Vpr, PVR, and $\mathrm{Q}_{\max }$ were not statistically significant. The risk, however, to present at least one episode of acute urinary retention, was 3 -fold more probable in patients who never used $\alpha 1$-blockers $(\mathrm{p}=0.044) \mathrm{OR}=$ 3.439 (95\% CI 1.05-11.06). Subjects under $\alpha$-blocker treatment were obstructed for a shorter period [mean $3.82 \pm 4.11$ vs. $6.14 \pm 4.33$ years $(\mathrm{p}=0.019)]$, which reflects the time receiving medication.

Bladder tissue from obstructed subjects showed high immunoreactivity to HIF-1 $\alpha$ (mean number of total positive cells $88 \pm 48.1$ ), which was diffusely distributed among positive cells and was mainly nuclear and only weakly cytoplasmic (Figure1). The specimens from the control group, showed no or weak, mainly cytoplasmic immunoreactivity to HIF-1 $\alpha(<0-2 \pm 0.0)$ (Figure-1). Cells expressing HIF-1 $\alpha$, both from obstructed and control group patients (in control group when present) were stromal cells located in different proportions between muscle bundles and submucosa, while the urothelium and the detrusor muscle did not show any kind of immunoreactivity. The difference among study cohort and control group was significant $(p<0.001)$.

The two groups did not differ in the number of HIF-1 $\alpha$ positive cells, (mean number $88.6 \pm 49.6$ in those under medication, $86.8 \pm 45.8$ in the later) ( $p$ $=0.78$ ). Stromal cells exhibited strong positive staining for HIF-1 $\alpha$, in both its nuclear and cytoplasmic components.

Twenty patients underwent urodynamic evaluation; the characteristics are summarized in Table-2. Nine patients were characterized as low immunoreactivity and 11 as high reactivity according to HIF-1 $\alpha$ positive cells. The 2 groups did not differ regarding age, IPSS, Vpr, PSA, PVR and Qmax. No difference was detected among urodynamic parameters between the two groups, while the lowest bladder pressure at which HIF-1 $\alpha$ was up-regulated was detected at PdetQmax $=60 \mathrm{~cm} \mathrm{H2O}$, which corresponded at high HIF-1 $\alpha$ protein expression (PdetQmax $101.1 \pm 29.1$ range $60-130 \mathrm{~cm} \mathrm{H} 2 \mathrm{O}$ ) (Table-2).

\section{COMMENTS}

In the present study, HIF-1 $\alpha$ expression was higher in subjects with BOO than controls, demon- 
Table 1 - Characteristics of the patients.

\begin{tabular}{|c|c|c|c|c|}
\hline & $\begin{array}{c}\text { Under Alpha-Blocker } \\
\text { Treatment } \\
\text { mean } \pm \text { SD (range) }\end{array}$ & $\begin{array}{l}\text { Without Treatment } \\
\text { mean } \pm \text { SD (range) }\end{array}$ & Control & p Value \\
\hline HIF-1 $\alpha$ positive cells $(\mathrm{N})$ & $\begin{array}{l}86.84 \pm 45.82 \\
(20-150)^{*}\end{array}$ & $88.60 \pm 49.69(0-175)^{*}$ & $0-2$ & 0.001 \\
\hline Age (yrs.) & $\begin{array}{c}69.55 \pm 4.2 \\
(60-75)^{*}\end{array}$ & $\begin{array}{c}67.86 \pm 9.09 \\
(48-86)^{*}\end{array}$ & $\begin{array}{l}59.6 \pm \\
(56-73)\end{array}$ & 0.076 \\
\hline IPSS & $\begin{array}{l}19 \pm 7.96 \\
(7-35)^{*}\end{array}$ & $\begin{array}{c}22.59 \pm 6.1 \\
(10-35)^{*}\end{array}$ & $\begin{array}{l}5.88 \pm 0.8 \\
\quad(5-7)\end{array}$ & 0.001 \\
\hline $\operatorname{Vpr}\left(\mathrm{cc}^{3}\right)$ & $\begin{array}{l}79.15 \pm 25.29 \\
(43-130)\end{array}$ & $73.82 \pm 28.99(35-136)$ & $\begin{array}{l}63.4 \pm 15.25 \\
\quad(52-90)\end{array}$ & 0.439 \\
\hline Time of BOO (yrs) & $\begin{array}{l}3.82 \pm 4.11 \\
(1-10)\end{array}$ & $\begin{array}{c}6.14 \pm 4.33 \\
(1-15)\end{array}$ & - & 0.019 \\
\hline PVR (mL/) & $\begin{array}{l}230.91 \pm 114.5 \\
\quad(80-250)^{*}\end{array}$ & $\begin{array}{c}180.59 \pm 110.21 \\
(10-300)^{*}\end{array}$ & $\begin{array}{c}5.75 \pm 8.95 \\
(0-25)\end{array}$ & $<0.001$ \\
\hline $\mathrm{Q}_{\max }(\mathrm{mL} / \mathrm{s})$ & $\begin{array}{c}5.89 \pm 3.21 \\
(2.01-12.4)^{*}\end{array}$ & $\begin{array}{l}6.41 \pm 4.65 \\
(2.2-15.6)^{*}\end{array}$ & $\begin{array}{c}19.88 \pm 3.64 \\
(15-25)\end{array}$ & 0.001 \\
\hline $\begin{array}{l}\text { Acute urinary retention }(\mathrm{N}) \\
\text { Yes } \\
\text { No }\end{array}$ & $\begin{array}{l}15 \\
25\end{array}$ & $\begin{array}{c}13 \\
7\end{array}$ & & $\begin{array}{c}0.044 \\
\text { OR }=3.439 \\
(95 \% \mathrm{CI} \\
1.052-11.069)\end{array}$ \\
\hline
\end{tabular}

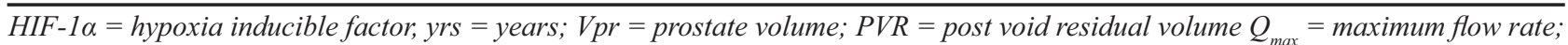
$N S=$ non significant $; O R=$ odds ratio; $C I=$ confidence interval. $* p<0.05$ with control group.

strating that obstructed bladder becomes hypoxic, as previously reported (12). The authors suggested that bladder stromal cells were those to perceive low oxygen tension, while the detrusor and the urothelium seems to be more resistant.

Another important finding is that HIF-1 $\alpha$ protein expression is the same among patients under treatment with $\alpha_{1}$-blockers who are finally operated and those without treatment, giving evidence that medication did not influence tissue hypoxia in chronic BOO. The role of $\alpha_{1}$-blockers in bladder metabolism and hypoxia has not been previously investigated, even though several papers have been published regarding the role of this medication on bladder function $(1,2)$.

Study group and control group were well balanced regarding age, IPSS, Vpr and other comorbid conditions, in an effort to avoid bias between the two groups, on factors that could influence tissue hypoxia (diabetes, hypertension, smoking, high cholesterol) (13). Chronic tissue ischemia results in detrusor smooth muscle replacement with collagen, followed by impaired contractility and overactivity with loss of bladder compliance (14).

However, the same changes are observed in chronic BOO, with detrusor dysfunction and tissue hypoxia being the result of high intravesical pressure, generated to overcome the resistance to flow. Bladder blood flow decreases during filling along with the rise of intravesical pressure. Before voiding, intravesical pressure increases, while bladder neck relaxes and the resistance to flow drops; a plateau phase is reached, where intraluminal pressure remains constant to achieve complete emptying. In BOO, this phase is prolonged and voiding may still be complete, at the cost, however, of tissue ischemia. In experimental 

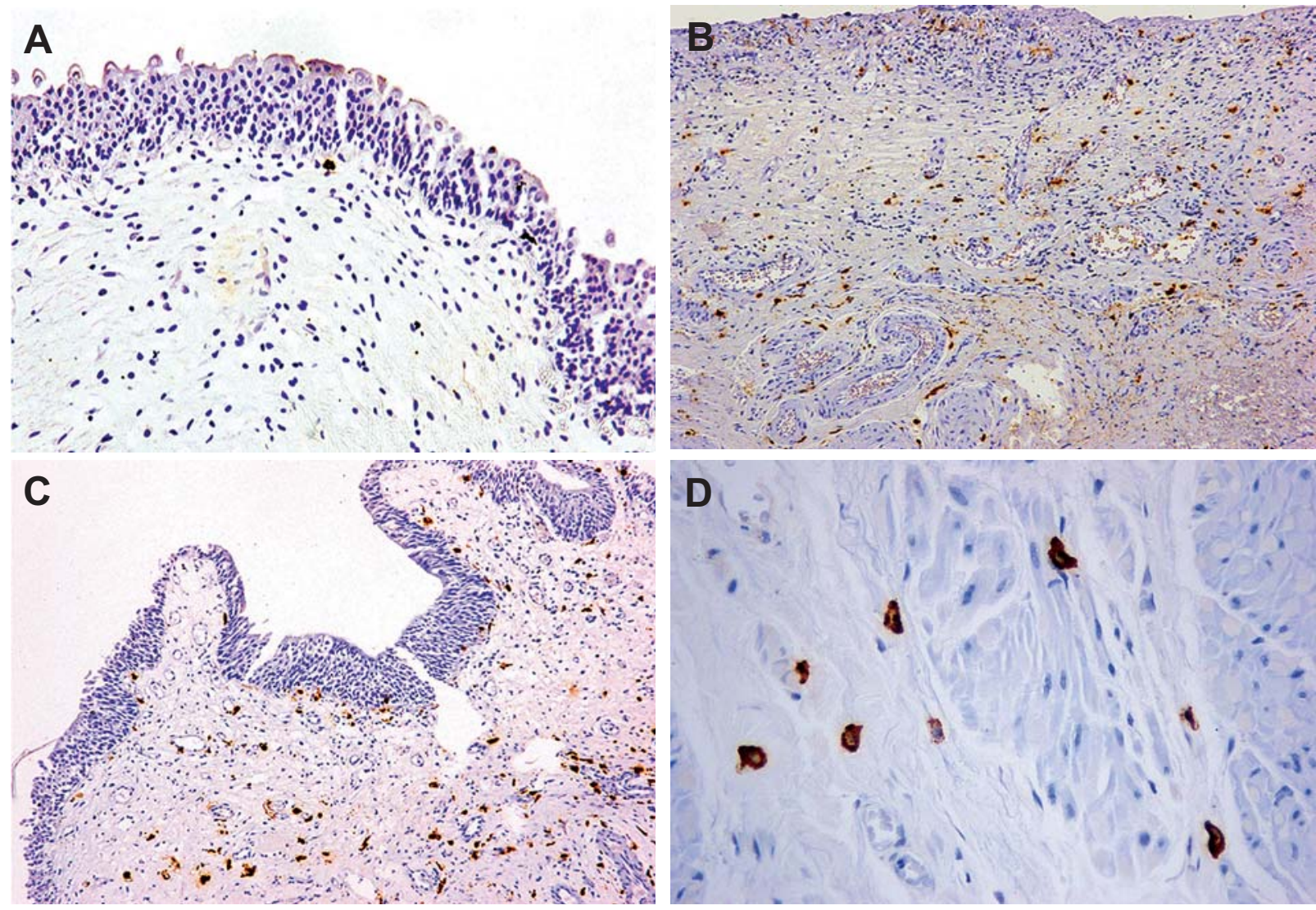

Figure 1 - Staining for HIF-1a (brown color) observed in stromal cells of the bladder wall. A) Negative staining in controls, B) Strong positive staining in obstructed patients receiving alpha-blocker, C) Obstructed patients without treatment exhibiting similar staining to $B$, and D) Prominent cytoplasmic and nuclear staining in a patient with bladder outlet obstruction (A, B, and CX100,D X400).

models with obstructed animals, during the voiding phase, bladder wall blood flow decreases to the same extent as in the non-obstructed animals. Nevertheless, since emptying is sustained, significant detrusor hy- poxia occurs and detrusor pressure becomes the main determinant of blood flow (15).

Pinggera and colleagues measured blood perfusion in arteries in the bladder neck and the prostate

Table 2 - Urodynamic parameters according to HIF-1a immunoreactivity.

\begin{tabular}{lccc}
\hline & $\begin{array}{c}\text { Low intensity } \\
\text { median } \pm \text { SD (range) }\end{array}$ & $\begin{array}{c}\text { high intensity } \\
\text { median } \pm \text { SD (range) }\end{array}$ & p Value \\
\hline PdetQmax (cm H2O) & $100.50 \pm 32.23(71-154)$ & $101.14 \pm 29.19(60-130)$ & 0.85 \\
Pdetmax (cm H2O) & $116.00 \pm 40.17(82-166)$ & $127.57 \pm 54.9(63-220)$ & 0.72 \\
PdeCL (cm H2O) & $64.0 \pm 25.26(20-81)$ & $81.83 \pm 32.9(17-186)$ & 0.76 \\
Qmax (mL/sec) & $5.97 \pm 3.50(1.7-10.2)$ & $5.54 \pm 4.70(2.0-15.6)$ & 0.56 \\
\hline
\end{tabular}

PdetQmax = Detrusor pressure at maximum flow rate; Pdetmax = Maximum detrusor pressure; $P C L=$ Detrusor closure pressure; Qmax = Maximun flow rate; intensity $=$ cut off point of 80 reactive cells/slide which represents the lowest $95 \%$ CI value. 
at different filing volumes using Doppler ultrasound, while they assessed the influence of $\alpha 1$-blockers in the perfusion of the same arteries during filling. They concluded that perfusion is reduced in LUTS patients and increases to almost normal levels after $\alpha 1$-blocker treatment, suggesting that treatment improved perfusion in the lower urinary tract (16). However, in the aforementioned work, blood flow at the dome and the posterior wall was not investigated, while perfusion was not measured during bladder emptying. The vessels that authors measured for perfusion were in the bladder neck and prostate and not those that travel in bladder wall (17), the vessels in the trigone are arranged in a looser network with more uniform and larger diameter (18). Therefore, there is no definite conclusion that treatment with a-blockers improved perfusion in the hall bladder.

In human bladders without obstruction, there is a 2-fold increase in bladder blood flow associated with filling, compared to the empty state, as measured with laser Doppler in the posterior wall (17). It seems that the posterior wall and the dome of the bladder are more vulnerable to bladder pressure $(17,18)$. The investigators also found that bladder blood flow reaches peak at detrusor pressure of 23 $\mathrm{cm} \mathrm{H2O}$. On the other hand, blood flow is decreased to approximately 1.2 times the base line flow, in detrusor pressure of $43 \mathrm{~cm} \mathrm{H} 2 \mathrm{O}$, which is measured at maximum cystometric capacity. However, despite the high pressure, it remains higher compared to the empty state. Additionally, those with decreased bladder compliance had lower perfusion at empty bladder, a smaller increase of blood flow with filling, and a lower perfusion at maximum cystometric capacity. Nevertheless, in this work it could not be addressed whether the causative factor for the low compliance was ischemia or the exact opposite (17). As the authors state, bladder perfusion still remains normal even at intraluminal pressure of $43 \mathrm{~cm} \mathrm{H} 2 \mathrm{O}$ which corresponds to filling at the maximum cystometric capacity. In obstructed patients, however complete voiding requires much higher pressures.

Recently it has been described that HIF- $1 \alpha$ expression was higher in patients with retention. It is known that urodynamics performed shortly after an episode of retention shows a decompensated bladder with intravesical pressures not exceeding $20-30 \mathrm{~cm}$
$\mathrm{H} 2 \mathrm{O}$. After a period however of 11 to 50 days detrusor regains its function and can generate intravesical pressures at maximum flow even of $81.6(35.2) \mathrm{cm}$ $\mathrm{H} 2 \mathrm{O}$ (17). It is common practice to wait at least several weeks after an acute episode of urinary retention before performing surgical treatment for $\mathrm{BOO}$, since prostatectomy immediately after such episode is associated with higher morbidity and mortality (19). Acute detrusor decompensation on the other hand and post void residual is a consequence of depletion of energetic reserves and HIF-1 $\alpha$ is known to participate in the cellular metabolism by inducing enzymes in the glycolitic pathway (12). These results may explain why HIF-1 $\alpha$ was found up-regulated in patients with retention as in our cohort of patients.

In the present study, tissue specimens were obtained from the dome of the bladder, since during filling the dome has the lowest perfusion. Therefore, we hypothesized that hypoxia would be more pronounced at this location (20). We also used urodynamics to identify the lowest bladder pressure at which HIF-1 $\alpha$ is up-regulated, although this was not possible. In our patients, the lowest detrusor pressure to detect HIF- $1 \alpha$ was at $60 \mathrm{~cm} \mathrm{H2O}$ and corresponded to a high protein expression. Furthermore, there was no difference among urodynamic parameters between high and low reactivity patients. The expression of HIF- $1 \alpha$ gives evidence that above the normal detrusor pressure for voiding (roughly $20-30 \mathrm{~cm} \mathrm{H} 2 \mathrm{O}$ ) the bladder becomes hypoxic.

The urodynamic effect of $\alpha 1$-blockers has been extensively explored in earlier studies. It has been found that treatment with $\alpha 1$-blockers increased average maximum flow rate to $2.9 \mathrm{~mL} / \mathrm{s}$ (range $0.9-5.6$ $\mathrm{mL} / \mathrm{s}$ ) and the PdetQmax decreased to average 17.4 $\mathrm{cm} \mathrm{H} 2 \mathrm{O}(38.2-0.0 \mathrm{~cm} \mathrm{H} 2 \mathrm{O})$ from a base line of $85.1 \mathrm{~cm}$ $\mathrm{H} 2 \mathrm{O}$ (range $70-100.4 \mathrm{~cm} \mathrm{H} 2 \mathrm{O}$ ) to $67.1 \mathrm{~cm} \mathrm{H} 2 \mathrm{O}$ (range $39.7-93 \mathrm{~cm} \mathrm{H} 2 \mathrm{O}$ ), but this interval is always above normal detrusor pressure, for non obstructed voiding (17-21). Patients in these studies however, experienced marked symptomatic improvement as assessed by IPSS, although still remaining obstructed. This may explain why these medications do not influence disease progression as defined by the need for invasive treatment and acute urinary retention (2). Recently, Barendrecht and associates questioned the fact that $\alpha 1$-blockers improve LUTS by reducing BOO. In this 
work, BOO index improved only slightly compared to IPSS and maximum flow, so the investigators stated that these medications function differently than relaxing prostate smooth muscle (22).

Our study is not without drawbacks. Firstly, we used immunohistochemistry to characterize bladders as hypoxic rather than quantify the levels of HIF-1 $\alpha$. Immunohistochemical evaluation of tissue protein expression is susceptible to intraobserver and interobserver variability, however, quantification of the HIF- $1 \alpha$ is not necessary for the evaluation of hypoxia, since we used the categorical nature of HIF- $1 \alpha$ protein expression in order to minimize, as possible, the aforementioned limitations. Additionally, we used HIF- $1 \alpha$ as a marker of tissue hypoxia, despite the fact that it can also be induced in non ischemic tissues. HIF- $1 \alpha$ accumulates in myocytes as an early response to mechanical stress in hearts with diastolic pressure increase, followed by enhanced expression of VEGF genes. Similarly, in obstructed bladders, HIF-1 $\alpha$ may also be induced by mechanical stress. Even if this is the case in BOO, treatment with $\alpha$-blockers does not decrease bladder wall tension to preobstructed levels giving a further stimulus to HIF-1 $\alpha$ induction. It would be interesting to verify if HIF-1 $\alpha$ levels normalize after the obstruction is relieved. We are also aware that urinary retention may affect HIF-1 $\alpha$ expression to those not receiving $\alpha 1$-blocker treatment (12).

\section{CONCLUSIONS}

Treatment with $\alpha$-blockers in obstructed patients does not seem to result in HIF-1 $\alpha$ down-regulation. It is likely that once obstruction has settled, medication does not change bladder metabolism, which continues to be under chronic stress. Further studies are needed to confirm the present results, and clarify the role of $\alpha 1$-antagonists on bladder homeostasis in chronic BOO.

\section{ACKNOWLEDGMENTS}

We would like to thank Douka Despina for her support to the study and Kemerli Maria for her assistance with the immunohistochemical analysis.

\section{CONFLICT OF INTEREST}

None declared.

\section{REFERENCES}

1. Lee E, Lee C: Clinical comparison of selective and non-selective alpha 1A-adrenoreceptor antagonists in benign prostatic hyperplasia: studies on tamsulosin in a fixed dose and terazosin in increasing doses. $\mathrm{Br} \mathrm{J}$ Urol. 1997; 80: 606-11.

2. McConnell JD, Roehrborn CG, Bautista OM, Andriole GL Jr, Dixon CM, Kusek JW, et al.: The long-term effect of doxazosin, finasteride, and combination therapy on the clinical progression of benign prostatic hyperplasia. N Engl J Med. 2003; 349: 2387-98.

3. Greenland JE, Brading AF: Urinary bladder blood flow changes during the micturition cycle in a conscious pig model. J Urol. 1996; 156: 1858-61.

4. Brading AF: Alterations in the physiological properties of urinary bladder smooth muscle caused by bladder emptying against an obstruction. Scand J Urol Nephrol Suppl. 1997; 184: 51-8.

5. Salceda S, Caro J: Hypoxia-inducible factor 1alpha (HIF-1alpha) protein is rapidly degraded by the ubiquitin-proteasome system under normoxic conditions. Its stabilization by hypoxia depends on redox-induced changes. J Biol Chem. 1997; 272: 22642-7.

6. Lee JW, Bae SH, Jeong JW, Kim SH, Kim KW: Hypoxiainducible factor (HIF-1)alpha: its protein stability and biological functions. Exp Mol Med. 2004; 36: 1-12.

7. Hoppeler H, Vogt M: Muscle tissue adaptations to hypoxia. J Exp Biol. 2001; 204: 3133-9.

8. Kietzmann T, Görlach A: Reactive oxygen species in the control of hypoxia-inducible factor-mediated gene expression. Semin Cell Dev Biol. 2005; 16: 474-86.

9. Chandel NS, Maltepe E, Goldwasser E, Mathieu CE, Simon MC, Schumacker PT: Mitochondrial reactive oxygen species trigger hypoxia-induced transcription. Proc Natl Acad Sci U S A. 1998; 95: 11715-20.

10. Duranteau J, Chandel NS, Kulisz A, Shao Z, Schumacker PT: Intracellular signaling by reactive oxygen species during hypoxia in cardiomyocytes. J Biol Chem. 1998; 273: 11619-24.

11. Birner P, Schindl M, Obermair A, Plank C, Breitenecker G, Oberhuber G: Overexpression of hypoxiainducible factor 1alpha is a marker for an unfavorable prognosis in early-stage invasive cervical cancer. Cancer Res. 2000; 60: 4693-6. 
12. Koritsiadis G, Stravodimos K, Koutalellis G, Agrogiannis G, Koritsiadis S, Lazaris A, et al.: Immunohistochemical estimation of hypoxia in human obstructed bladder and correlation with clinical variables. BJU Int. 2008; 102: 328-32.

13. Ponholzer A, Temml C, Wehrberger C, Marszalek M, Madersbacher S: The association between vascular risk factors and lower urinary tract symptoms in both sexes. Eur Urol. 2006; 50: 581-6.

14. McVary KT: Erectile dysfunction and lower urinary tract symptoms secondary to BPH. Eur Urol. 2005; 47: 838-45.

15. Greenland JE, Brading AF: The effect of bladder outflow obstruction on detrusor blood flow changes during the voiding cycle in conscious pigs. J Urol. 2001; 165: 245-8.

16. Pinggera GM, Mitterberger M, Pallwein L, Schuster A, Herwig R, Frauscher F, et al.: alpha-Blockers improve chronic ischaemia of the lower urinary tract in patients with lower urinary tract symptoms. BJU Int. 2008; 101: 319-24.

Correspondence address:

Dr. Stavros Tyritzis

LAIKO Hospital, Department of Urology

Athens University Medical School

17 Agiou Thoma str.

11527, Athens, Greece

Fax: + $00302109327-744$

E-mail: statyr@freemail.gr
17. Kershen RT, Azadzoi KM, Siroky MB: Blood flow, pressure and compliance in the male human bladder. J Urol. 2002; 168: 121-5.

18. Miodonski AJ, Litwin JA: Microvascular architecture of the human urinary bladder wall: a corrosion casting study. Anat Rec. 1999; 254: 375-81.

19. Dubey D, Kumar A, Kapoor R, Srivastava A, Mandhani A: Acute urinary retention: defining the need and timing for pressure-flow studies. BJU Int. 2001; 88: 178-82.

20. Batista JE, Wagner JR, Azadzoi KM, Krane RJ, Siroky MB: Direct measurement of blood flow in the human bladder. J Urol. 1996; 155: 630-3.

21. Kortmann BB, Floratos DL, Kiemeney LA, Wijkstra H, de la Rosette JJ: Urodynamic effects of alpha-adrenoceptor blockers: a review of clinical trials. Urology. 2003; 62: 1-9.

22. Barendrecht MM, Abrams P, Schumacher H, de la Rosette JJ, Michel MC: Do alpha1-adrenoceptor antagonists improve lower urinary tract symptoms by reducing bladder outlet resistance? Neurourol Urodyn. 2008; 27: 226-30.

Accepted after revision: August 11, 2009

\section{EDITORIAL COMMENT}

Benign prostatic obstruction will induce bladder hypoxia, which could be detected by elevation of bladder tissue HIF-1- $\alpha$. The authors studies the effects of $\alpha$-blocker treatment on bladder HIF-1- $\alpha$ regulation during lower urinary tract obstruction and concluded that $\alpha$ blocker has no effect on bladder tissue HIF-1- $\alpha$ expression. It is an interesting study, but some bias from the current groups need to be cleared.

As all of the biopsy patients are alpha-blocker non-responder, I would contend that the responders may show lower HIF-1 $\alpha$ than the non-responder. 
By means of laser Doppler flowmeter, Lin et al. demonstrated that the obstructed bladders from rabbits with partial outlet obstruction had significantly lower blood flow than the ischemic bladders (1). After 8 weeks partial outlet obstruction, bladder from rabbits with supplement of L-arginine showed significantly greater contractile function compared with the no-treatment group (2). The study demonstrated that increasing blood flow by stimulating nitric oxide synthase significantly protected the bladder from partial bladder outlet obstruction dysfunctions. Therefore, the patients with lower urinary tract obstruction might still be able to get partial recovery of bladder flow, reverse of ischemia change, and improve bladder function through some therapy.

\section{REFERENCES}

1. Lin WY, Mannikarottu A, Li S, Juan YS, Schuler C, Javed Z, et al.: Correlation of in vivo bladder blood flow measurements with tissue hypoxia. World J Urol. 2009; 4. [Epub ahead of print]

2. Lin WY, Levin RM, Chichester P, Leggett R, Juan YS, Johnson A, et al.: Effects of L-arginine and L-NAME on chronic partial bladder outlet obstruction in rabbit. Am J Physiol Regul Integr Comp Physiol. 2007; 293: R2390-9.

\author{
Dr. Yao-Chi Chuang \\ Division of Urology \\ Chang Gung Memorial Hospital \\ Kaohsiung Medical Center \\ Kaohsiung, Taiwan \\ E-mail: chuang82@ms26.hinet.net
}

\section{EDITORIAL COMMENT}

This well written paper offers new insight novel mechanism of action $\alpha$-blocker treatment my have on the obstructed bladder. This study lends further evidence that $\alpha$-blocker's benefit in cases of bladder outlet obstruction (BOO) may be more on the bladder than urethral outlet.

George and associates from Athens assessed whether $\alpha 1$-blocker treatment, in chronic BOO, influences bladder tissue ischemia. They studied 60 patients with $\mathrm{BOO}, 40$ with and 20 without $\alpha 1$-blockers, respectively. At time of transurethral or suprapubic prostatectomy, bladder biopsies were taken for immunohistochemically stained for Hypoxia Inducible Factor- $1 \alpha$ (HIF-1 $\alpha$ ). Ten patients with non muscle invasive bladder cancer underwent transurethral resection of the tumor served as control group.
Dr. Michael B. Chancellor Neurourology Program William Beaumont Hospital Royal Oak, MI, 48073, USA E-mail: chancellormb@gmail.com 